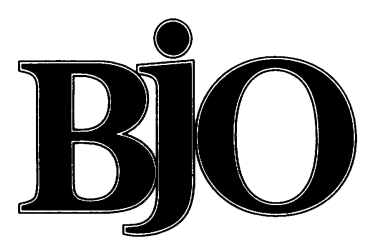

British Journal of Ophthalmology

\title{
Editorials
}

\section{To preserve or not to preserve, is that the question?}

Over 40 years ago, microbial contamination of eyedrops was reported as a significant risk factor in a series of communications describing bacterial keratitis associated with their use. ${ }^{1-5}$ Most of the solutions were of unpreserved fluorescein, but sulphonamides, silver proteinates, alkaloids, methylcellulose, anaesthetics, and sodium chloride were also contaminated. ${ }^{45}$ The predominant contaminant and cause of corneal ulceration was Pseudomonas aerugi$n o s a .^{5}$ Also implicated were penicillin eyedrops causing keratitis among industrial workers following removal of corneal foreign bodies. ${ }^{6}$

From these events arose the need for standardised, aseptic preparation of eyedrops which are preserved and dispensed sterile in multidose containers; either plastic with screw on cap or glass with a pipette dispenser. Additionally, in North America at least, in house formulation of eyedrops has, with some exceptions, been discontinued since the economy of scale associated with commercial manufacture of these units makes bulk purchase of commercially used eyedrops more cost effective. Paradoxically, however, an annoying disadvantage to the use of sterile, preserved eyedrops in multidose containers is the presence of the preservative itself. Benzalkonium chloride, a cationic surfactant, and thiomersal (thimerosal), an organic mercurial, have been two commonly used eyedrop preservatives. The former is a known cause of toxic epithelial changes ${ }^{7}$ and the latter, severe hypersensitivity reactions. ${ }^{8}$ As a consequence, patients using eyedrops preserved with these, as well as other chemicals, are at risk of developing ocular surface disorders. ${ }^{9}$ This is particularly true if the eyedrops must be applied frequently as are artificial tears in patients with dry eyes. ${ }^{10}$

To avoid preservative induced surface problems while maintaining eyedrop sterility, unit dose vials of various solutions have long been available for physician use in the office or operating theatre. They are now readily available for patient use, chiefly in delivering preservative-free ocular lubricants. However, as noted in the paper by Oldham and Andrews, in this issue of the $B F O$ ( $p$ 588), the cost of form, fill, and seal machinery considerably increases the expense of unit dose eyedrops compared with preserved, multidose preparations. Further, these authors describe the use of unit dose eyedrops as cumbersome at home and inconvenient when away from home. Also, since the cost of equipment to manufacture unit dose medication is prohibitively expensive, they suggest the home use of multidose bottles of preservative-free eyedrops formulated aseptically and freshly dispensed from the Moorfields Eye Hospital pharmacy. Home refrigeration at $2-8^{\circ} \mathrm{C}$ is recommended to control microbial contamination with a 7 day expiration following initial use. The reported results on the antimicrobial efficacy of the medication itself, plus refrigeration, would certainly seem supportive of this approach to controlling microbial contamination in unpreserved eyedrops. None the less, there are some concerns which should be addressed.

The first issue is concern regarding patient compliance. For any patient, but particularly an elderly one, it may be cumbersome and uncomfortable to have to go to the home refrigerator several times a day, and instil a chilled eyedrop. In addition, to leave the domiciliary environment for any length of time requires carrying the eyedrops about in a refrigerated container or in a non-refrigerated state. It is likely that inconvenience plus frequency will equal patient non-compliance! If so, hours, perhaps days of nonrefrigeration may occur. Given likely contamination of the pipette dropper, a worrisome population density of bacteria within the container of eyedrops could exist by day 7 .

Secondly, microbial contamination may occur while the medication is refrigerated. Some mesophilic and many psychrophilic bacteria can multiply at temperatures between $4^{\circ} \mathrm{C}$ and $8^{\circ} \mathrm{C}$. In fact, at least one case of microbial keratitis caused by such an organism has been reported. ${ }^{11}$ Home refrigerators are hardly sterile, and even with compliance, such contamination is a point of concern.

Thirdly, the use of non-toxic preservatives/new technology varies from country to country. Chemical preservation of eyedrops with chlorobutanol, polyquaternium-1, or sorbic acid may offer an alternative to the more toxic effects of benzalkonium chloride if formulation compatibility is possible. In the USA, one ocular lubricant is preserved with a boric acid-perborate mixture, resulting in a $50-55 \mathrm{ppm}$ hydrogen peroxide preservation which instantly decomposes on the ocular surface into water and oxygen. ${ }^{12}$ In Germany, a specially configured eyedrop container is used to deliver preservative-free eyedrops. ${ }^{13}$ Unfortunately, there are no large population study data available on its ability to resist microbial contamination. In France, an anti-allergy, preserved eyedrop formulation is dispensed in a multidose plastic squeeze bottle. The preserved drop passes through an expurgating filter to reach the ocular surface, presumably preservative free. Clinical trials on the efficacy of this device are also lacking. Another development in polymer technology permits the incorporation of a 
benzalkonium adsorbing resin in the tip of some multidose, preserved eyedrops removing $96-99 \%$ of the preservative from the eyedrop before it reaches the ocular surface (VPF: virtually preservative free) (Harold Slovin, CibaVision Ophthalmics, Atlanta, Georgia, personal communication).

Unfortunately, these devices are of the plastic, squeeze container design with screw on caps; a design reported prone to bacterial colonisation of the space between the bottle tip and the cap or along the threads of the container cap. Preservation of the eyedrops in such instances has not prevented drop associated microbial keratitis. ${ }^{14-16}$ Actually, in preserved eyedrops, the glass bottle pipette tip dispenser is less prone to contamination. ${ }^{17}$ Patient use and time since initial utilisation are additional factors contributing to microbial contamination of multidose preserved eyedrops. ${ }^{18}$

So where then do we go? Preserved or unpreserved? Without clinical trials, it is difficult to be certain. Probably the treating physician should use unpreserved, refrigerated eyedrops with an inhibitory buffer system such as borate-boric acid only when preserved eyedrops have been observed to induce an ocular surface disorder. What is certain is, as Oldham and Andrews conclude, that the 'onus remains on medical practitioners to ensure that unpreserved multidose eyedrops are only used in appropriate circumstances to ensure safe and effective therapy'.

LOUIS A WILSON

Emory Eye Center, Emory University School of Medicine, 1365B Clifton Road, NE, Atlanta, GA 30322, USA
1 McCulloch JC. Origin and pathogenicity of $P$ pyocyanea in conjunctival sac. Arch Ophthalmol 1943;29:924-36.

2 Hogan MJ. The preparation and sterilization of ophthalmic solutions. Calif Med 1949;71:414-6.

3 Theodore FH. Contamination of eye solutions. Am $f$ Ophthalmol 1951;34:1764.

4 Theodore FH. Practical suggestions for the preparation and maintenance of sterile ophthalmic solutions. Am 7 Ophthalmol 1952;35:656-9.

5 Vaugh DG, Jr. The contamination of fluorescein solutions with special reference to Pseudomonas aeruginosa (Bacillus pyocyaneus). Am $\mathcal{f}$ Ophthalmol 1955;39:55-61.

6 Bignell JC. Infection of the cornea with B pyocyaneus. Br $\mathcal{O}$ Ophthalmol 1951; 35:419-23.

7 Pfister RR, Burnstein N. The effects of ophthalmic drugs, vehicles and preservatives on corneal epithelium: a scanning electron microscopy study. Invest Ophthalmol 1976;15:246-59.

8 Wilson L, McNatt J, Reitschel R. Delayed hypersensitivity to thimerosal in soft contact lens wearers. Ophthalmology 1981;88: 804-9.

9 Imperia PS, Lazarus HM, Botti RE, Jr, Lass JH. An in vitro method for measuring ophthalmic preservative cytotoxicity. $\mathscr{f}$ Toxicol Cutan Ocular Toxicol 1986;5:309-17.

10 Lemp M. Management of the dry eye patient. Int Ophthalmol Clin 1994;34: 101-13.

11 Gini GA. Ocular infection caused by Psychrobacter immobilis acquired in the hospital. $\mathcal{f}$ Clin Microbiol 1990;28:400-1.

12 Gentle 'GenTeal' lubricant eye drops. Atlanta, GA: CibaVision Ophthalmics.

13 Teping C, Wiedemann B. Das COMOD-System. Eine konservierungsmittlefreies Mehrdosenbehaltmis fur Augentropfen. Klin Monatsbl Augenheilkd 1994;205:210-7.

14 Templeton WC III, Eiferman RA, Synder JW, Melo JG, Rabb MJ. Serratia keratitis transmitted by contaminated eye drops. Am $\mathcal{F}$ Ophthalmol 1982;93: $723-6$.

15 Schein OD, Wasson PJ, Boruchoff SA, Kenyon KR. Microbial keratitis associated with contaminated ocular medications. Am $\mathcal{f}$ Ophthalmol 1988;105: 361-5.

16 Schein OD, Hibbard PL, Starck T, Baker AS, Kenyon KR. Microbial contamination of in use ocular medicines. Arch Ophthalmol 1992;110:82-5.

17 Coad CT, Osata MS, Wilhelmus KR. Bacterial contamination of eye drop dispensers. Am $\mathcal{f}$ Ophthalmol 1984;98:541-51.

18 Geyer O, Bottone EJ, Podos SM, Schumer RA, Asbell PA. Microbial contamination of medications used to treat glaucoma. Br $\mathcal{f}$ Ophthalmol contamination of 